\title{
Research on the Present Situation of MOOC in China Based on CNKI Metrology Visualization Analysis
}

\author{
Yahong Zhou \\ School of Foreign Studies \\ Anhui Sanlian University \\ Hefei, China 230601
}

\author{
Rui Dai \\ School of Foreign Studies \\ Anhui Sanlian University \\ Hefei, China 230601
}

\begin{abstract}
In order to accurately grasp the current situation of MOOCs research in China, this paper makes use of the content analysis method to make a statistical analysis of the academic papers published in China's CSSCI journals from 2012 to 2016 , to analyze and summarize from the 5 aspects that the number of papers, the source journals, the subject distribution, hot spot analysis and research content, with a view to provide a reference for the follow-up study of MOOCs class.
\end{abstract}

Keywords-MOOCs; CNKI

\section{INTRODUCTION}

MOOCs (Massive Open Online Course) refers to the largescale open online courses, and this concept is first presented in Connectivism and Connective Knowledge by Dave Cormier and Bryan Alexander in 2008. In 2012, Coursera, Udacity, edX these three major international MOOC platforms have been established to mark the first year of international MOOCs is coming. By the end of 2012, Netease Study.163.com came online; In 2013, China's universities have joined the international MOOC platform, and in the same year Tsinghua University established a XuetangX; In 2014 Netease with Higher Education Press launched the Chinese University MOOC platform, while in the same year Shanghai Jiaotong University go live their own CNMOOC platform. All these mark that China is entering the time of MOOC.

With the domestic MOOC is blossoming in full swing, the study of MOOC is also rapidly developing. Reviewing the relevant research results, and its analysis and summary, will be conducive for the MOOC to promote the development and reform of China's education. This paper studies the core journals of MOOC, which is included in the CNKI, and analyzes the research status, existing problems and research trends of MOOC, so as to provide a reference for the follow-up study of MOOC.

\section{RESEARCH METHODS AND TOOLS}

\section{A. Research Methods}

Content analysis is a kind of research method to objectively

This paper is one of the research results of the school-level quality engineering project "Large-scale Online Open Course (MOOCs) Business English Negotiation" (16zlgc020) and the Province-level quality engineering project "Large-scale Online Open Course (MOOCs) Demonstration Project English Foreign Trade Correspondence" (2016mooc152). and systematically quantify and describe the obvious communication content [1]. Based on the content analysis method, this paper systematically analyzes and summarizes the related articles of MOOC published in the core journals of China during 2012-2016 from the five aspects that the number of papers, source journals, subject distribution, research hotspots and research contents. So as to discuss the research status, existing problems and future development of MOOC.

\section{B. Object of Study}

For this paper, I searched on the CNKI based on the "MOOC" and "MOOCs" as the key words, and the CSSCI journals as the source of literature. The "MOOC" was first appeared in the domestic core journals in 2012. So the search starting time is 2012, and as of December 2016, a total of 725 articles were received. Except 1 annual review and 3 interviews, there are 721 articles available in total.

\section{RESEARCH RESULTS AND ANALYSIS}

\section{A. Quantitative Analysis of MOOC}

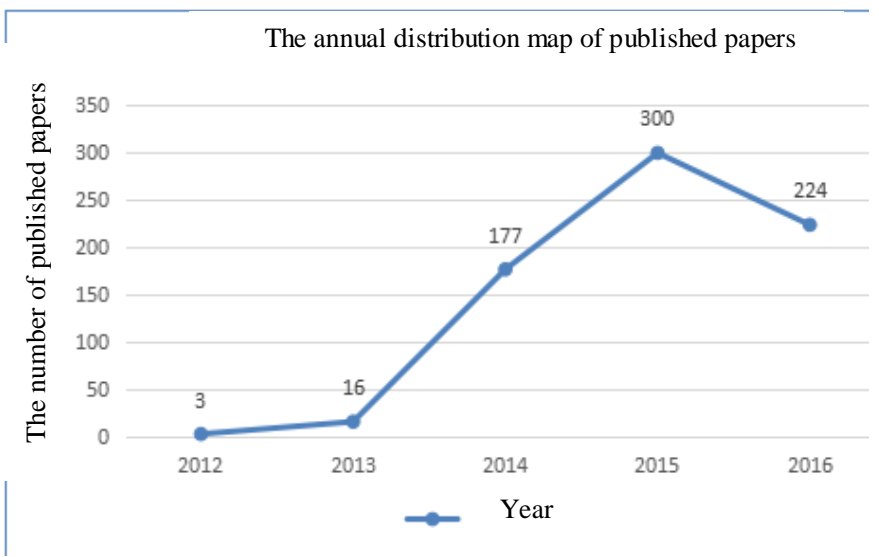

Fig. 1. The annual distribution map of academic papers of MOOC.

As can be seen from "Fig. 1", the domestic research for MOOC started in 2012. With the arrival of the first year of international MOOCs (2012), the domestic study of MOOC sprang up. According to the number of published papers, the domestic MOOC study has gone through three stages: (1) the initial stage (2012-2013), during this 2 years only a total of 19 
papers were published, which indicated that MOOC study has not been widely concerned. During this period, the domestic colleges and universities have just started to join the world's three major MOOC platforms, and at the end of 2012 the Netease Study.163.com has just started online. So the MOOC construction is still in the early stages; (2) growth period (2014), this year the number of papers soared to 177, which indicated that the MOOC has gotten the attention of scholars. During this period, the Chinese University MOOC, XuetangX and other domestic MOOC platforms have entered the orbit. On the Netease Study.163.com there were more millions of people online learning every day, the maturity of MOOC construction also provides a research basis for the MOOC study; (3) Booming period (2015-2016), the total number of papers in the past two years reached 524, especially the total number of papers in 2015 exceeded that in the previous three years, which showed that the MOOC study has gotten a great concern of the researchers. But according to the dropped number of papers in 2016, it indicated that MOOC study tended to be stable.

\section{B. Analysis of the Source Journals of Paper}

TABLE I. SOURCE JOURNALS DISTRIBUTION

\begin{tabular}{|c|c|c|c|c|c|}
\hline $\begin{array}{c}\text { Source } \\
\text { journals }\end{array}$ & $\begin{array}{c}\text { The } \\
\text { number } \\
\text { of } \\
\text { publishe } \\
\text { d } \\
\text { articles }\end{array}$ & $\begin{array}{l}\text { Perce } \\
\text { ntage }\end{array}$ & $\begin{array}{c}\text { Source } \\
\text { journals }\end{array}$ & $\begin{array}{l}\text { The } \\
\text { number } \\
\text { of } \\
\text { publishe } \\
\text { d } \\
\text { articles }\end{array}$ & $\begin{array}{l}\text { Perce } \\
\text { ntage }\end{array}$ \\
\hline $\begin{array}{l}\text { Modern } \\
\text { Educationa } \\
1 \\
\text { Technolog } \\
\text { y }\end{array}$ & 57 & 9.97 & $\begin{array}{l}\text { Modern } \\
\text { Distance } \\
\text { Education } \\
\text { Research }\end{array}$ & 26 & 4.55 \\
\hline $\begin{array}{l}\text { CNYCED } \\
\mathrm{U}\end{array}$ & 46 & 8.04 & $\begin{array}{l}\text { Library and } \\
\text { Information } \\
\text { Service }\end{array}$ & 25 & 4.37 \\
\hline $\begin{array}{l}\text { China } \\
\text { Educationa } \\
1 \\
\text { Technolog } \\
\text { y }\end{array}$ & 45 & 7.87 & $\begin{array}{l}\text { Science- } \\
\text { Technology } \\
\& \\
\text { Publication }\end{array}$ & 23 & 4.02 \\
\hline $\begin{array}{l}\text { E- } \\
\text { education } \\
\text { Research }\end{array}$ & 39 & 6.82 & $\begin{array}{l}\text { Researches } \\
\text { In Library } \\
\text { Science }\end{array}$ & 19 & 3.32 \\
\hline $\begin{array}{l}\text { China } \\
\text { University } \\
\text { Teaching }\end{array}$ & 37 & 6.47 & $\begin{array}{l}\text { Library } \\
\text { Work and } \\
\text { Study }\end{array}$ & 17 & 2.97 \\
\hline $\begin{array}{l}\text { Open } \\
\text { Education } \\
\text { Research }\end{array}$ & 34 & 5.94 & $\begin{array}{l}\text { New } \\
\text { Century } \\
\text { Library }\end{array}$ & 15 & 2.62 \\
\hline $\begin{array}{l}\text { Distance } \\
\text { Education } \\
\text { Journal }\end{array}$ & 28 & 4.90 & $\begin{array}{l}\text { Modern } \\
\text { Distance } \\
\text { Education }\end{array}$ & 15 & 2.62 \\
\hline \multicolumn{4}{|l|}{ Toal } & 426 & 74.48 \\
\hline
\end{tabular}

These 721 papers were published in 30 kinds of core journals, this paper only counts the journals with more than issued 15 articles. "Table I" shows the 14 journals that occupy $74.48 \%$ of the total issued articles, among which the six kinds of magazines: Modern Educational Technology, CNYCEDU, China Educational Technology, E-education Research, China University Teaching, Open Education Research issued a total of 224 articles, accounting for about $35 \%$ of the total number of papers. It can be seen that these journals are the core of MOOC study. The data shows that the study papers are mainly concentrated in the educational journals, especially in the core journals such as educational technology and distance education. This shows that the core journals of educational technology are the important platform for scholars to exchange their MOOC study, and the educational technicians are the important force for MOOC study.

\section{Analysis of Subject Distribution}

CNKI divides all subjects into 10 categories with 168 special categories. The CNKI metrology visualization analysis shows that the MOOC study mainly focuses on educational theory and education management, library and information and digital library, higher education, computer software and computer application, publication and foreign language writing, and the total MOOC study papers of these six subjects account for $90.85 \%$ of the total amount. Among them, the educational papers (education theory and education management, higher education) account for $69.53 \%$ of the total amount, especially the education theory and education management ones account for $60.96 \%$, which shows that the basic theory of education is the focus of the current MOOC study. The library information and digital library ones account for $15.94 \%$ of the total amount, indicating that the library is the earlier and rapider development subject of MOOC study. Wang Youfu pointed out that the library is one of the areas to faster tracking and applying new information technology. At the beginning when the MOOC got attention, some scholars have written about the influence of MOOC on university library and the strategy discussion [2]. Higher education papers account for $8.57 \%$ of the total amount, which indicates that colleges and universities is also an important research field of MOOC study, their teachers is one of the main staff of MOOC study. "Fig. 2"

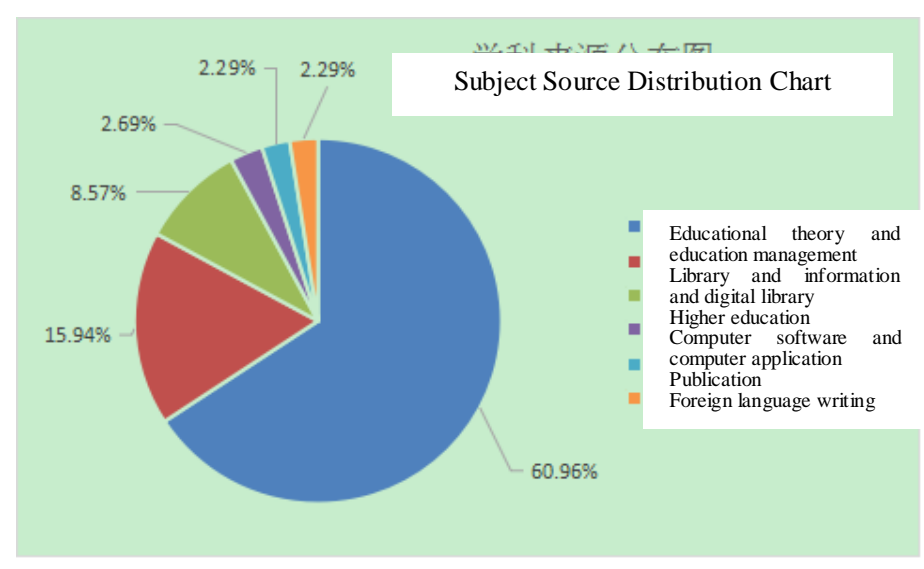

Fig. 2. MOOC study subject source distribution map.

\section{Research Hotspot Analysis}

Word frequency analysis is a bibliometric method to use the frequency that the key words or subject terms, which can explain or express the core content of the literature, occur in a certain research literature to determine the research hotspot and development trends of this field[3]. The subject terms or key word reflects the core content of a literature. If a key word or a 
subject term is repeated in a certain field, it indicates that this key word or subject term is the research hotspot in this field. According to the CNKI metrology visualization analysis,
"Table II" is the high frequency keywords appearing in MOOC study.

TABLE II. High FREQUENCY KeYWORdS OF MOOC STUDY

\begin{tabular}{|c|l|l|l|l|l|}
\hline Rank & Higi-frequency key words & Frequency & Rank & High-frequency key words & Frequency \\
\hline 1 & MOOC & 231 & 6 & Online Education & 35 \\
\hline 2 & University Library & 56 & 7 & SPOC & 33 \\
\hline 3 & Flipped Classroom & 50 & 8 & Teaching Mode & 25 \\
\hline 4 & $\begin{array}{l}\text { Large-scale Open Online } \\
\text { Course }\end{array}$ & 36 & 9 & Library & 23 \\
\hline 5 & Higher Education & 36 & 10 & Teaching Reform & 17 \\
\hline
\end{tabular}

"Fig. 3" is the view of research hotspots based on the literature, which each node is a keyword, and the size of the node shows the frequency of keywords, the lines between nodes shows the co-occurrence relationship between the keywords, the thickness of the lines between the keywords shows the frequency of co-occurrence.

From "Fig. 3", we can know that MOOC, flipped classroom, university library, online education, higher education and library is the core key words of MOOC study, that is, the hotspot and focal point of the current MOOC study. The cooccurrence relationship between MOOC and flipped classroom is the closest; while the co-occurrence relationship between MOOC and the university library, micro-learning class, higher education, online education is just closer.

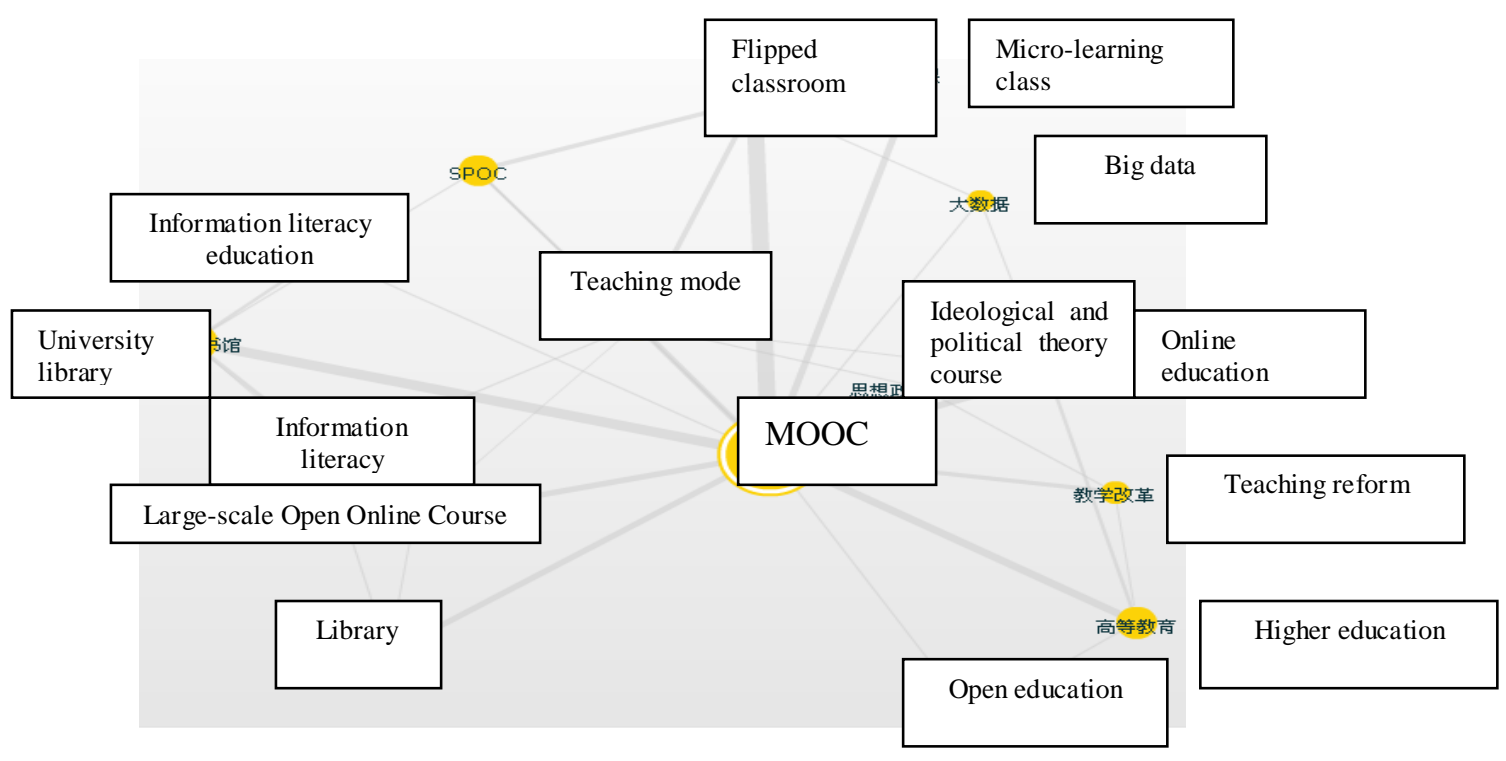

Fig. 3. Hotspot view of MOOC study in the past five years

\section{E. Content Analysis of MOOC Stusy}

Through the thematic content analysis of these 721 papers, the contents of the nearly five years MOOC study can be summarized in the following aspects.

\section{1) MOOC study}

In the early development of MOOC, it mainly introduced the origin, nature, concept, characteristics, value, etc.. According to Kant's four basic questions about rationality, Liu Hehai discuss the four basic questions of MOOC: what is "what is the MOOC", what can MOOC do ", what should be done?" "Prefer MOOC to do what ", thus revealing the nature of MOOC [4]. Chen Xiaogeng, Wang Dingming think that compared with the traditional curriculum, MOOC has largescale, open, network and innovation of four characteristics [5].

2) College and university and MOOC

MOOC has a far-reaching impact on the higher education of colleges and universities, college teachers are also the main force of MOOC research, the current MOOC and university research is mainly the following aspects: 1) college MOOC course, including college course design and making, MOOC teaching practice, etc., focusing on empirical research, such as Rosa to English writing tasks, for example, the study of learners survey data show that, MOOC learning to improve student learning participation and mutual 2) the professional development of college teachers, Kang Anfeng pointed out that on positioning the role of teachers, MOOC rising is both a 
crisis and a turning point, teachers engaged in MOOC teaching only to replace the team led by individual led, by strengthening the teacher community team building, promoting collaborative innovation, in order to effectively resolve the crisis caused by modern information technology on the identity of teachers, properly responded to the challenges of transition [7]; 3) Learners' learning on MOOC model is mainly from the learners' angle to study the students' learning mode, learning efficiency and so on MOOC model. Ru Zongyang and others summarized the process of logistic regression research in online learning field. On this basis, the learning behavior indicator is constructed from the MOOCs online learning process, and the MOOCs learning data are analyzed by using the logistic regression, and the influence of learners' online learning behavior on academic record is explored[8]; 4) Based on the teaching reform of MOOC, such as the flipped classroom, the micro-learning class, the online education, the SPOC and other teaching models study based on MOOC, Dai Zhaohui and Chen Jianlin, through questionnaire survey and interview, explore the influencing factors and the relationship role of the college English flipped classroom based on the idea of MOOC, and then put forward the ways and means of college English flipped classroom diversification based on the idea of MOOC [9]; 5) As the MOOC's influence on higher education and the development of MOOC in higher education, MOOC has brought the higher education unprecedented opportunities and challenges. MOOC promotes multiple level cooperation of credit and teacher exchange between the universities, but also promotes the integration of the higher education and continuing education. Thus the popularity of higher education has a new development channel [10], but MOOC in higher education also encountered some difficulties, that there will objectively exist the phenomenon of high dropout rate with the high autonomy in MOOC learning, low-cost MOOC further encourages students who is in the state of hesitation to quit MOOC learning, this is the important reason for MOOC experience cold wave [11].

\section{3) Library and MOOC}

Library science is one of the earliest disciplines to study MOOC. Copyright service, library service transformation and information literacy education and others are the hotspots for library studying MOOC. MOOC's rapid development profoundly affects the education-related industries, of which the library is one. Library plays a copyright adviser, or resource navigation, or teaching support, or information literacy, or other roles in MOOC, to achieve a new function position. The library will face many practical challenges when carries out the MOOC services, so the corresponding strategic countermeasures in marketing promotion, cross-border cooperation and mechanism innovation and other aspects should be implemented[12]. Zhao Kun has pointed out that in the MOOC environment, public libraries need to make some service innovations in the aspects like operation mode, copyright guidance, professional service, classification training, promotion and so on, in order to enhance the social value of public library [13].

\section{4) Press and MOOC}

MOOC have a great impact on the traditional education, at the same time it will also attract the attention of the press. With the MOOC moving forward, there many new requirements of teaching materials will come up. Li Xueju has pointed out that MOOC promoted the transformation and upgrading of the education publishing in digital content production, teaching design and curriculum innovation, professional teaching service team, platform knowledge communication demand, information teaching management and other aspects to allround knowledge service.

\section{CONCLUSION}

With the analysis of the relevant literature, we can find out that MOOC has been widely concerned in domestic, and the MOOC study is generally rapidly growing in the nearly 5 years The research content of MOOC is gradually turning to practical research from the initial introduction and review of MOOC, especially to the application research, and its research directions are more diverse, deeper and wider. From the perspective of subject distribution and literature source, the MOOC study mainly focuses on 6 fields which is educational theory and education management, library and information and digital library, higher education, computer software and computer application, publication and foreign language writing. While most of the literature source periodicals are educational journals, which are mainly related to higher education.

In general, China's MOOC study is still in the initial stage, it will slowly be cooling from the initial fanatical state, and then turn to stable and finally rational state. The development of MOOC in China will also encounter difficulties and challenges. Looking forward to the future trends of MOOC study, in the research content, MOOC study will no longer stay in the theoretical research, but be more inclined to application promotion research, that is, to focus on MOOC's production and design in the specific course, management and evaluation, the learner's knowledge transformation and learning model in MOOC mode and so on, and the MOOC's localization innovation will be the focus of future research; in the field of study, due to the high autonomy of MOOC is difficult to meet the needs of basic education, the MOOC study will continue to focus on higher education, adult continuing education, and distance education, but the rise of SPOC will be an opportunity for the MOOC development of basic education.

\section{REFERENCES}

[1] Wang Guohua, Yu Shuyu, Huang Huifang, Hu Yan. Current Research Status of Blended Learning in China[J]. Distance Education in China, 2015.02

[2] Wang Youfu. Transformation and Response of Library Science Curriculum Construction in the MOOC Context[J]. Document, Information \& Knowledge, 2014

[3] Qiu Junping, Wen Fangfang. A Visual Analysis of the Hotspots and Frontiers of Library and Information Science in Recent Five Years Based on the Metrical Study of 13 Highly Influential Foreign Journal Source[J]. Journal of Library Science In China, 2011.03

[4] Liu Hehai, Zhang Shuyu, Zhu Lilan. Analysis on the Essence, Connotation and Value of MOOC[J]. Modern Educational Technology, 2014.12

[5] Chen Xiaogeng, Wang Dingming. Analysis on the Development and the Main Features of MOOC[J], Modern Educational Technology, 2013.11 
[6] Luo Sha. A Study on the Evaluation of Scaffolding Peer in MOOC Environment - Taking English Writing Task as an Example[J]. Computer-assisted Foreign Language Education, 2016.12

[7] Kang Anfeng. Analysis on the Role Orientation and Remodeling of MOOC Teachers[J]. Higher Education Exploration, 2016. 12

[8] Zong Yang, Sun Hongtao, Zhang Hengguo, Zheng Qinhua, Cheng Li. Logistic Regression Analysis of MOOCs Learning Behavior and Learning Effect[J]. Distance Education in China, 2016.05

[9] Dai Zhaohui, Chen Jianlin. A Study on the Influencing Factors of College English Flipped Classroom Based on MOOC[J]. Computerassisted Foreign Language Education, 2016.05

[10] Wang Qiong. The Osmotic Effects of MOOC Sports on Higher Education[J]. Open Education Research, 2016.6

[11] Zhu Qingfeng. The Dilemma and Theoretical Choice of the Development of Higher Education in China[J]. Exploring Education Development, 2014

[12] Liu Limin. The Role of Foreign Library in MOOC Service and Its Development Strategy[J]. Modern Information, 2016.4

[13] Zhao Kun. Research on Public Library Service in MOOC Times[J]. New Century Library, 2016.09

[14] Li Xueju. From the Publication of Teaching Materials to the Knowledge Service --- the Integration Development Opportunities of Higher Education Publication in MOOC Times[J]. Science-Technology \& Publication, 2015(5) 